Research Article

Animal Genetics

\title{
Transcriptomic evidences of local thermal adaptation for the native fish Colossoma macropomum (Cuvier, 1818)
}

\author{
Luciana Mara Fé-Gonçalves $^{1}$ (D) , José Deney Alves Araújo ${ }^{2}$ (D) , Carlos Henrique dos Anjos dos Santos ${ }^{1}$ (D) \\ and Vera Maria Fonseca de Almeida-Val ${ }^{1}$ \\ ${ }^{1}$ Instituto Nacional de Pesquisas da Amazônia, Laboratório de Ecofisiologia e Evolução Molecular, Manaus, \\ AM, Brazil. \\ ${ }^{2}$ Universidade de São Paulo, Laboratório de Biologia de Sistema Computacional, São Paulo, SP, Brazil.
}

\begin{abstract}
Brazil has five climatically distinct regions, with an annual average temperature difference up to 14 으 between the northern and southern extremes. Environmental variation of this magnitude can lead to new genetic patterns among farmed fish populations. Genetically differentiated populations of tambaqui (Colossoma macropomum Cuvier, 1818), an important freshwater fish for Brazilian continental aquaculture, may be associated with regional adaptation. In this study, we selected tambaquis raised in two thermally distinct regions, belonging to different latitudes, to test this hypothesis. De novo transcriptome analysis was performed to compare the significant differences of genes expressed in the liver of juvenile tambaqui from a northern population (Balbina) and a southeastern population (Brumado). In total, 2,410 genes were differentially expressed (1,196 in Balbina and 1,214 in Brumado). Many of the genes are involved in a multitude of biological functions such as biosynthetic processes, homeostasis, biorhythm, immunity, cell signaling, ribosome biogenesis, modification of proteins, intracellular transport, structure/cytoskeleton, and catalytic activity. Enrichment analysis based on biological networks showed a different protein interaction profile for each population, whose encoding genes may play potential functions in local thermal adaptation of fish to their respective farming environments.
\end{abstract}

Keywords: Transcriptome, tambaqui, population, temperature, thermal adaptation.

Received: November 14, 2019; Accepted: July 13, 2020.

\section{Introduction}

The large teleost fish, Colossoma macropomum $\mathrm{Cu}-$ vier, 1818 (popularly called "tambaqui" or "cachama negra") is a native species found in the Amazonas and Orinoco rivers (Araújo-Lima and Goulding, 1998), being economically important for Brazilian continental aquaculture (IBGE, 2016). Belonging to the Characiformes order and the Serrasalmidae family (Mirande, 2010), an adult tambaqui may reach a weight of $30 \mathrm{~kg}$ and a length of $1 \mathrm{~m}$ (Saint-Paul, 1986). Due to these traits, the tambaqui has become the primary commercial resource in Amazonian aquaculture and fisheries for its good zootechnical aspects: high level of adaptability to different culture systems, easy manipulation and reproduction in captivity by hormonal induction, high growth rate, and, of course, consumer market acceptance due to the quality of its meat (Moro et al., 2013; Morais and O'Sullivan, 2017). As a result, the intensification of its production has been spread by fish farming, which is located in four distinct geographic regions of Brazil (Ostrensky et al., 2008).

Send correspondence to Luciana Mara Fé-Gonçalves. Instituto Nacional de Pesquisas da Amazônia, Laboratório de Ecofisiologia e Evolução Molecular, Avenida André Araújo 2936, 69067-375, Petrópolis, Manaus, AM, Brazil. E-mail: lucianamfeg@gmail.com.
Brazil displays a climatic variability which can be divided into five regions; Northern, Northeastern, CentralWestern, Southeastern, and Southern (Alvares et al., 2013). However, the most climatically distinct Northern and Southeastern regions are highlighted in our study. According to Köppen's classification of climates, the Northern region is naturally dominated by a humid equatorial climate (Af climate), with an annual average temperature of $27.1^{\circ} \mathrm{C}$ (ranging from 22.3 to $32.6^{\circ} \mathrm{C}$ ), while the Southeastern region presents a humid, temperate climate (Cwa climate), with an annual average temperature of $20.1^{\circ} \mathrm{C}$ (varying from 9.4 to $28.0^{\circ} \mathrm{C}$ ). In winter, cold fronts originating from the Atlantic polar mass may cause frost (Alvares et al., 2013).

Considering seasonal temperature variation between climatic zones, recent studies have investigated the environmental adaptations of species based on genomic approaches, which reflect biological processes that are important in adaptive evolution (Yi et al., 2016). Genetic variation within populations has suggested that captive tambaquis already show signs of local adaptation to regions with different climatic conditions (Santos et al., 2016; Nunes et al., 2017; Gonçalves et al., 2019). Moreover, specific thermal adaptations of these populations have revealed differential expression of genes, displaying critical roles in metabolic processes for fish homeostasis, such as circadian rhythm, cell prolifera- 
tion, energy metabolism and protein modification (Dragan, 2019).

Transcriptome analysis of non-model organisms is one of the most important approaches for providing insights into the adaptive evolution of species in response to their living environments (Yi et al., 2016). However, under the current perspective of global climate change, such molecular informations may be particularly valuable in the conservation of species which are threatened by extreme environmental challenges (Bellard et al., 2014). In general, fish are highly able to respond plastically to a myriad of environmental changes, but whether their plastic responses are beneficial seems to depend on the environmental variable that they are being subjected to (Schulte, 2001). Climate changes may negatively affect fish populations living close to their thermal comfort zone (Pörtner and Peck, 2010), and fish, particularly in the Amazon region, will be those most threatened (Fé-Gonçalves et al., 2018; Campos et al., 2019).

The genetic basis for the tambaqui fish has been developed in recent years. Thus, the present study provides a novel investigation regarding the regional adaptation of tambaqui populations raised in two thermally distinct regions of Brazil based on a comparison of transcriptome profiles.

\section{Material and Methods}

\section{The historical formation of tambaqui broodstocks}

The origin of farmed populations of tambaqui in Brazil dates 54 years ago. The first tambaqui broodstocks were reared between 1966 and 1970 from a few wild fish sourced from the Amazon basin (DNOCS, 2009) and the Peruvian Amazon (Araújo-Lima and Goulding, 1988). The offspring were sent to central-western, northern, northeastern, and southeastern regions to form the first local broodstocks. During the same period, adult tambaqui fish from Peruvian Amazon was taken to the UEPI (Experimental Center of Intensive Fish Farming) of DNOCS (National Department of Works for Drought Control) located in Ceará state (Araújo-Lima and Goulding, 1988). In the mid-1980s, juveniles sourced from DNOCS were also sent to other Brazilian fish farms, including Brumado Fish Farming in São Paulo state. Considering the timeline of the tambaqui breeding stock formation in Brazil, Balbina's population has been isolated for about 50 years from the Brumado population, which is equivalent to at least 50 generations (Gonçalves et al., 2019).

\section{Liver sampling}

Twenty juvenile tambaquis were collected ex-situ from two fish farms located in the northern and southeastern regions of Brazil (Figure 1). Sampling was carried out during the dry season when regional climate variables were similar between both sites. Thena $(n=10 ; \sim 26 \mathrm{~g}$ and 1 population from Balbi0 cm) was collected in June 2016, at the beginning of the Amazonian "summer" period (Fisch et al., 1998), with temperatures varying between 23 to $31^{\circ} \mathrm{C}$ (Climatempo, 2019). The population from Brumado $(n=10$; $\sim 60 \mathrm{~g}$ and $13 \mathrm{~cm}$ ) was collected during the summer of February 2016, when temperature varied from 18.8 to $28^{\circ} \mathrm{C}$ (CPTEC/INPE, 2019). At the time, the water temperature of the rearing tanks was $29.5^{\circ} \mathrm{C}$ in Balbina and $21^{\circ} \mathrm{C}$ in Brumado; the level of dissolved oxygen ranged from 5 to 7 $\mathrm{mg} \cdot \mathrm{L}^{-1}$.

For tissue sampling from each population, fish (42 $\mathrm{g} \pm$ 4.7 and $11 \mathrm{~cm} \pm 0.4$ ) were anesthetized and euthanized by cervical sectioning according to Brazilian Guidelines from the National Board of Control and Care for Ethics in the use of Experimental Animals (CONCEA, 2013). Twenty liver samples were immediately stored in RNAlater ${ }^{\circledR}$ Stabilization Solution (Thermo Fisher Scientific, Massachusetts, USA) to ensure the preservation of the ribonucleic acid (RNA) during transport to the Laboratory of Ecophysiology and Molecular Evolution (LEEM/COBio/INPA), Manaus, Amazonas state, Brazil. In the laboratory, samples were removed from RNAlater ${ }^{\circledR}$, washed in RNase-free water (Qiagen, Hilden, DE), dapped dry on an absorbent paper tissue (Whatman, GE Healthcare Life Sciences, Maidstone, UK), and then stored at $-80{ }^{\circ} \mathrm{C}$ until extraction of the RNA. Herein, the liver was analyzed tissue due to its essential metabolically responses under environmental stress (Lemgruber et al., 2013; Logan and Buckley, 2015).

\section{Library construction for RNA sequencing}

Total RNA was extracted from the tambaqui livers using RNeasy ${ }^{\circledR}$ Mini Kit (Qiagen, Hilden, DE) protocol. Approximately $20 \mathrm{mg}$ tissue was homogenized in lysis buffer in a TissueLyser II (Qiagen, Hilden, DE) for $2 \times 2$ minutes at 20 $\mathrm{Hz}$. Automated purification of RNA was performed on a QIACube robotic workstation (Qiagen, Hilden, DE) using silica-membrane technology. The quality and quantity of extracted RNA were accurately checked using both an RNA 6000 Nano Bioanalyzer chip (Agilent Technologies, Santa Clara, USA) and a NanoDrop 2000 Spectrophotometer (Thermo Fisher Scientific, Massachusetts, USA). All the RNA samples were free of gDNA and had a suitable RNA yield $(\sim 0.7 \mu \mathrm{g})$ and optimal purity (average $\mathrm{RIN}=9.3$, $\mathrm{A}_{260}: \mathrm{A}_{280}$ and $\mathrm{A}_{260}: \mathrm{A}_{230}$ ratios $=2.0$ ). Before library construction, three samples of total RNA were pooled, totaling six RNA-Seq libraries, with three biological replicates for each tambaqui population (Balbina and Brumado).

All procedures for constructing and sequencing of RNA-Seq libraries were carried out in the Molecular Biology Laboratory of LEEM/INPA following the Illumina protocols. The mRNA was isolated from the total RNA $(0.72 \mu \mathrm{g}$ eluted in $50 \mu \mathrm{L}$ ) using oligo d(T) 25 magnetic beads bound to the poly (A) tail of the mRNA. Then, the first and second strands of complementary DNA (cDNA) were synthesized, and a single adenine (A) nucleotide was added to the end 3' of the fragments. Adapters were ligated to the cDNA fragments and a Polymerase Chain Reaction (PCR) was performed to enrich these fragments. cDNA libraries were prepared using the reagents provided in the TruSeq RNA Library Sample Preparation Kit v2 (Illumina, San Diego, USA). 


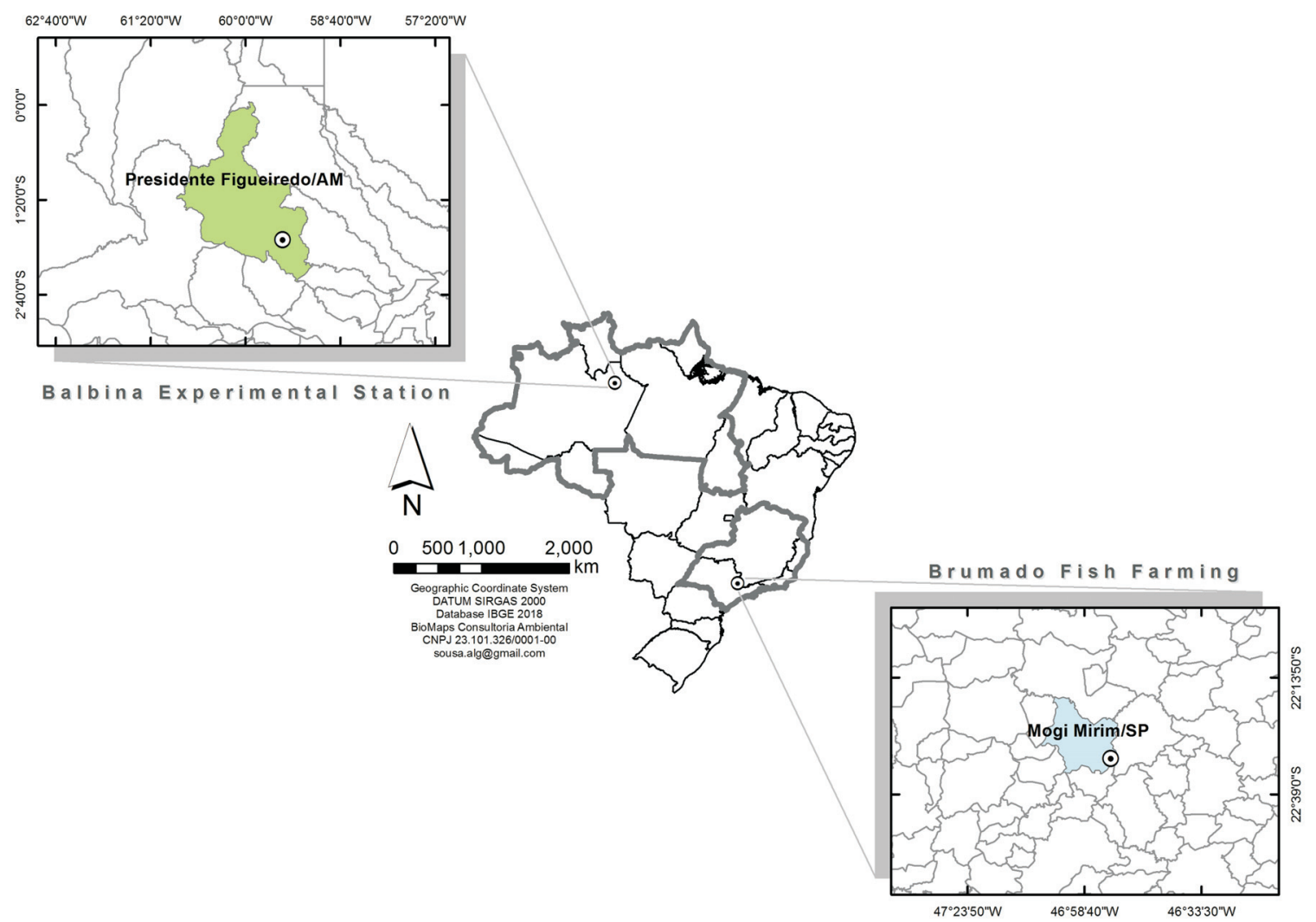

Figure 1 - Map of the sampling sites of two tambaqui populations from different regions of Brazil. The northern (Balbina Center of Technology, Training and Production in Aquaculture, CTTPA - SEPA/SEPROR, Balbina, Amazonas state - 1'55'54.4"S; 59 $24^{\circ} 39.1^{\prime \prime} \mathrm{W}$ ) and southeastern (Brumado Fish Farming, Mogi Mirim, São Paulo state - 22 ${ }^{\circ} 31^{\prime} 16.00^{\prime \prime S} ; 46^{\circ} 53^{\prime} 5.71$ "W) populations are raised in regions that display climate variability typically found in Brazil, according to Köppen's climate classification (Alvares et al., 2013).

The absolute quantification of cDNA libraries was measured on a ViiA 7 Real-Time PCR System (Thermo Fisher Scientific, Massachusetts, USA) using the KAPA SYBR $^{\circledR}$ FAST qPCR Master Mix (Kapa Biosystems, Wilmington, USA). Normalized cDNA libraries were clustered using the MiSeq Reagent Kit v2 (500-cycles) and sequenced on an Illumina MiSeq platform in three sequencing paired-end runs $(2 \times 250$ cycles $)$. These sequence data have been submitted to the National Center for Biotechnology Information/Sequence Read Archive (NCBI/SRA) databases under accession number PRJNA547332 (https://www.ncbi.nlm.nih.gov/sra).

\section{Bioinformatic analysis}

Analyses of the high-throughput RNA sequencing were performed at the Bioinformatics Laboratory of LEEM/INPA. The quality of sequenced reads was checked using the FastQC v.0.11.6 program (Andrews, 2010). The low-quality reads (Q-score $\leq 20)$ were trimmed by removing the adaptor sequences, and filtering the reads with less than 50 base pairs (bp) were performed using the Trimmomatic v.0.36 program (Bolger et al., 2014). Due to the absence of the complete genome for Colossoma macropomum species, we choose to use the de novo transcriptome assembly using the Trinity v.2.5.1 program (Grabherr et al., 2011). In addition, programs that assisted Trinity were used to assemble the transcriptome with the Bowtie2 v.2.3.3.1 (Langmead and Salzberg, 2012), and calculate the abundance of transcripts using the RSEM v.1.3.0 program (Li and Dewey, 2011) and R/Bioconductor packages v.3.3.2 (Bates et al., 2004), respectively.

Differential expression was quantified into up- and downregulated genes using the edgeR v.3.16.5 program (Robinson et al., 2009) of R/Bioconductor package. The assumed False Discovery Rate (FDR) was $\leq 0.05$ in order to correct $P$ values, and the data generated by the RSEM were used to calculate the fold change values of $\geq 2$. The differentially expressed genes (DEGs) were annotated with the BLASTx v.2.7.1+ program (Altschul et al., 1997), against the database of Uniprot/TrEMBL proteins (class Actinopterygii) and Swiss-Prot for non-redundant proteins, with $e$-value 1e-5. The Trinotate tool v.3.1.1 (https://trinotate.github.io/) was used to classify the DEGs according to the three general categories of Gene Ontology (GO) annotation: i) Biological Process (BP); ii) Cellular Component (CC); and iii) Molecular Function (MF).

Further analysis on Network Analyst (https://www.networkanalyst.ca/) was performed to construct relevant biological networks based on Protein-Protein Interaction (PPI) starting from a list of DEGs, using their official names and fold change values. NetworkAnalyst also allows performing functional enrichment analysis of significantly 
expressed GO terms according to the Kyoto Encyclopedia of Genes and Genomes (KEGG) database (Xia et al., 2014).

\section{Results}

Six cDNA libraries were constructed from the liver of juvenile tambaquis raised on the Balbina and Brumado fish farms. Three RNA-Seq runs performed on the Illumina MiSeq platform yielded 106,161,098 million (M) raw reads, with an average of $8,846,758 \mathrm{M}$ reads per library. After quality trimming (Q-score $\leq 20$ and removal of reads of length $\leq$ $50 \mathrm{bp}), 100,945,530 \mathrm{M}$ filtered reads were saved. About $95 \%$ of the total reads sequenced were assembled for de novo analysis and aligned; 166,819 contigs were assembled, and the average length was $912 \mathrm{bp}$, with an N50 value of 1,777 bp. The assembled bases totaled 152,281,627 M. Considering only those genes with a FDR $\leq 0.05$ and fold change $\geq 2$, a total of 2,410 genes showed significant differential expression between the two populations (Balbina versus Brumado). Of these, 1,196 (49.6\%) genes were found in the Balbina population, whereas 1,214 (50.4\%) genes were differentially expressed in the Brumado population. The overview of the de novo transcriptome statistics for the two populations of Colossoma macropomum is described in Table 1.

Regarding the functional classification of the DEGs, only the upregulated genes were annotated through GO terms: BP - Biological Process, CC - Cell Component, and MF - Molecular Function. In the population from the Balbina farm, 3,443 terms were successfully assigned into 703 GO subcategories: BP, 1,684; CC, 318 and MF, 1,441. For the population from the Brumado farm, 4,260 terms were categorized into $851 \mathrm{GO}$ subcategories: BP, 1,854; CC, 442 and MF, 1,964. GO representation of the top 30 upregulated terms identified in each population is shown in Figures 2 and 3, respectively. Forty-nine upregulated terms were shared in the two populations of tambaqui (Table 2).

Table 1 - Summary of the Illumina sequencing statistics.

\begin{tabular}{lcc}
\hline & Balbina & Brumado \\
\hline Raw reads & $57,361,634$ & $48,799,464$ \\
Min. raw reads & $8,873,256$ & $7,426,829$ \\
Max. raw reads & $9,963,942$ & $8,570,267$ \\
Average raw reads & $9,560,272$ & $8,133,244$ \\
Trimmed reads & $54,363,724$ & $46,581,806$ \\
Min. trimmed reads & $8,295,129$ & $6,990,030$ \\
Max. trimmed reads & $9,465,852$ & $8,173,557$ \\
Average trimmed reads & $9,060,621$ & $7,763,634$ \\
DE genes upregulated & 622 & 616 \\
Upregulated genes annotated by BLASTx & 413 & 468 \\
Upregulated terms assigned GO terms & 3,443 & 4,260 \\
DE genes downregulated & 574 & 598 \\
Downregulated genes annotated by BLASTx & 426 & 389 \\
Downregulated terms assigned GO terms & 4,734 & 3,821 \\
\hline
\end{tabular}

Overall, the genes commonly expressed between populations were related to several biosynthetic processes, homeostasis, biorhythm, immunity, cell signaling, ribosome biogenesis, metabolism of proteins, protein folding/modification, intracellular transport, structure/cytoskeleton and catalytic activity.

The two biological networks were constructed from the DE genes upregulated in the liver of both populations. A fully correlated seed node (or hubs) list is given in Tables S1 and S2. Each generated PPI network was composed for a suitable number of nodes (proteins) and edges (interactions between nodes); the Balbina population's PPI presented 752 nodes and 948 edges, whereas the one of Brumado population contained 671 nodes and 818 edges.

Enrichment analysis of the PPI network from each population showed a total of 36 KEGG pathways (Figure 4). Furthermore, enrichment categories based on GO terms for Biological Process were identified in both populations, as listed in Table 3. Seventy-four seed nodes were highlighted in the protein interaction network of the Balbina population (Figure 5). Proteins biologically involved in the metabolism of carbohydrates and lipids, reproduction, protein folding, and transport were represented in enriched hubs. However, the PPI network containing 70 seeds from the Brumado population showed another metabolic profile, with hub genes encoding proteins that participate in cellular homeostasis, response to external stimulus (oxygen radical, hypoxia and heat), RNA processing, signal transduction and protein import (Figure 6). Taken together, four putative functional categories involved in local adaptation of tambaqui to their respective farming sites are related to: i) energy metabolism; ii) protein folding; iii) cellular homeostasis; and iv) circadian rhythm.

\section{Discussion}

In order to investigate the candidate genes potentially involved in the adaptation of fishes to new or constantly changing environments, the introduction of deep-sequencing technologies has provided a revolutionary tool for the precise measurement of transcript levels (Oomen and Hutchings, 2017). In the present study, we employed an RNA sequencing approach to compare the transcriptomic profile of two populations of artificially farmed tambaqui from tropical and subtropical zones in Brazil. In total, 2,410 differentially expressed genes (1,196 in Balbina and 1,214 in Brumado) which are involved in a multitude of biological functions may assign valuable information into the particular metabolic processes of each population related to regional adaptation.

It is well known that temperature drives a physical influence on the environmental adaptation of natural fish populations which live in distinct climate regions (Schulte, 2001). Based on an RNA-seq analysis, evidence for local adaptation was identified in three loaches from different climatic zones in China (Yi et al., 2016). In these species of Misgurnus, population-specific adaptations were linked to 59 candidate genes playing functions in energy metabolism, 


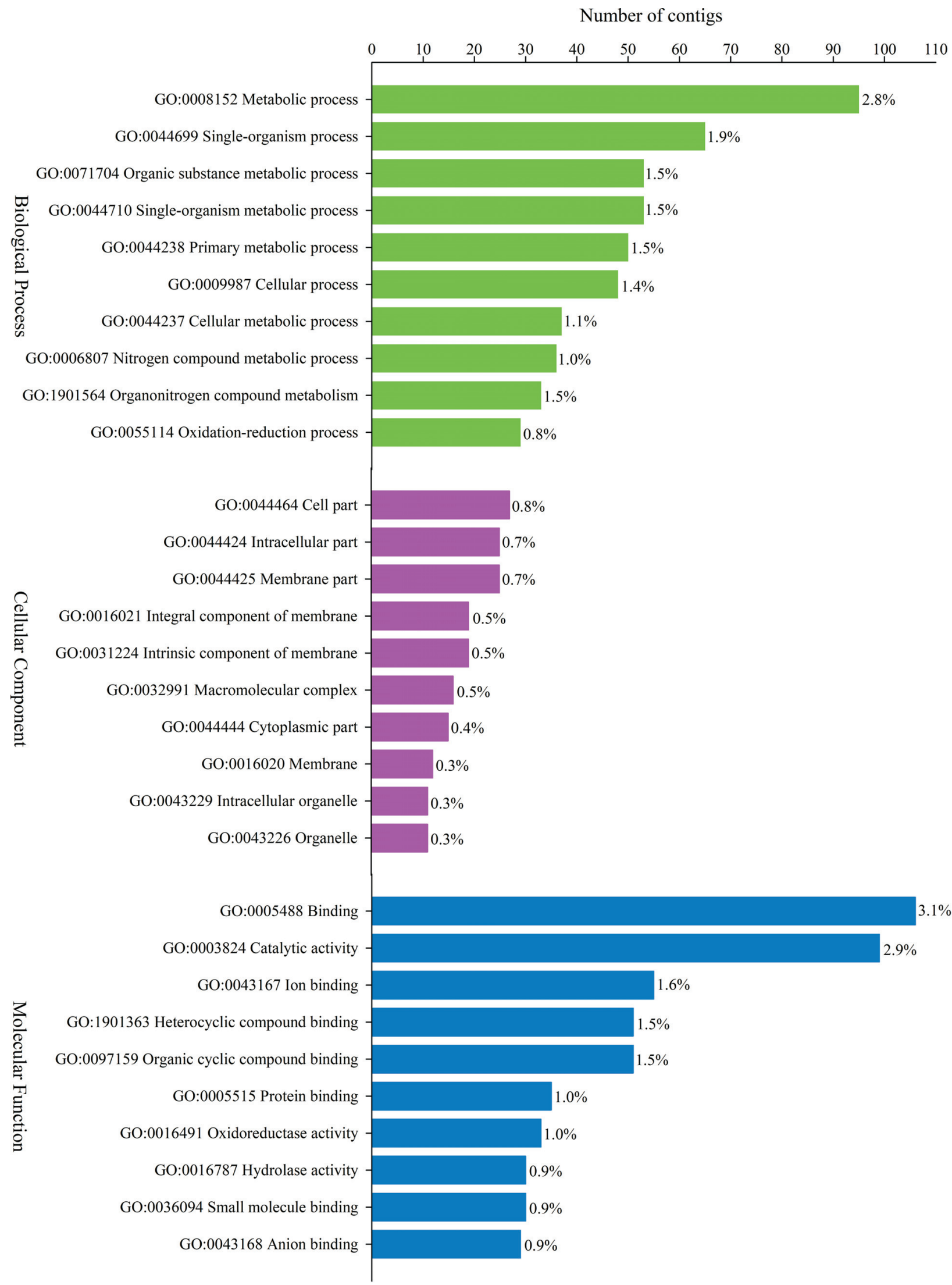

Figure 2 - The top 30 terms classification of the contigs significantly upregulated in Balbina population and separated into three functional Gene Ontology (GO) categories: Biological Process (green bars), Cell Component (purple bars) and Molecular Function (blue bars). The percentages indicate the representation of genes that belong to each category. 


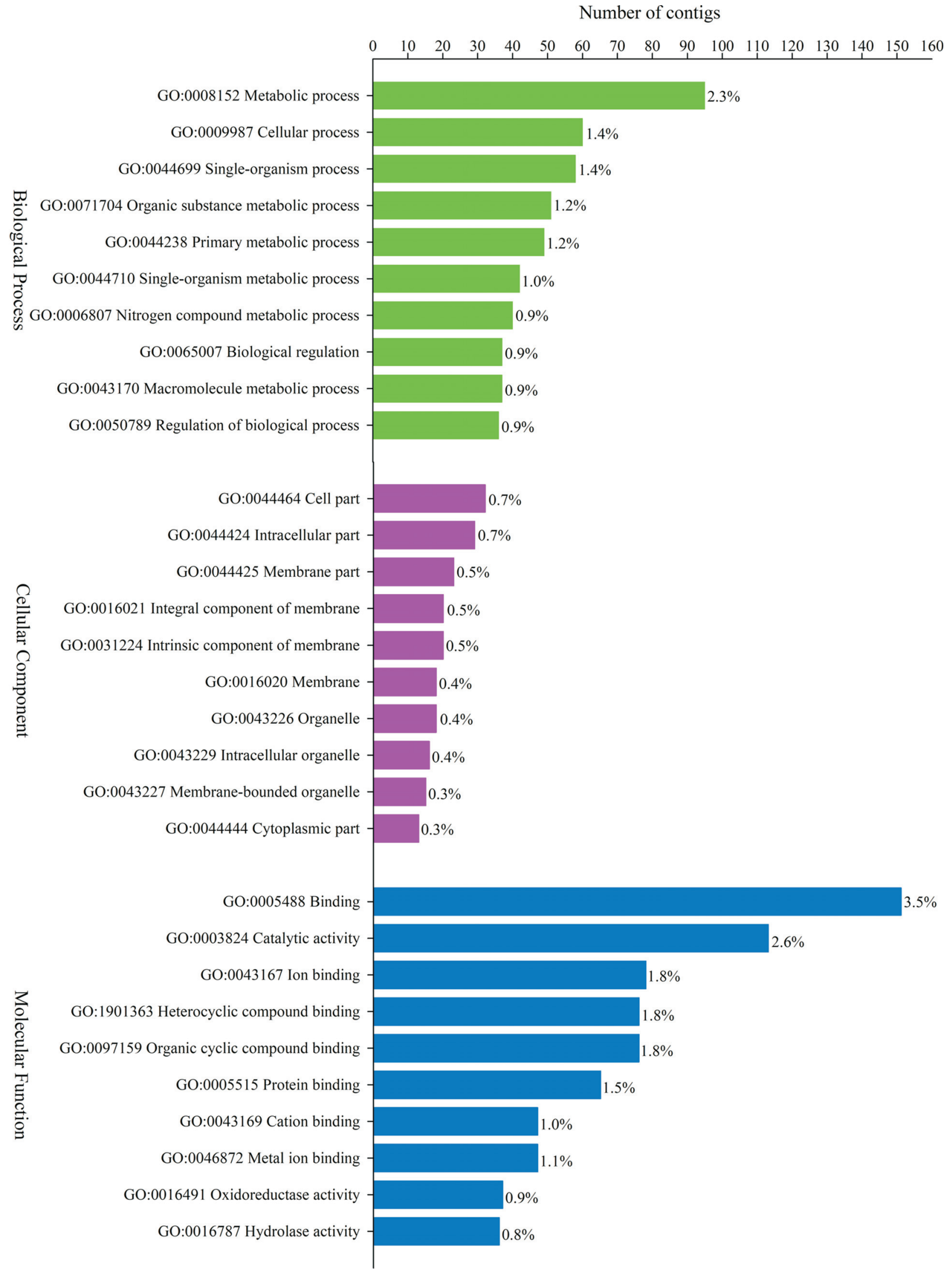

Figure 3 - The top 30 terms classification of the contigs significantly upregulated in Brumado population and separated into three functional Gene Ontology (GO) categories: Biological Process (green bars), Cell Component (purple bars) and Molecular Function (blue bars). The percentages indicate the representation of genes that belong to each category. 
Table 2 - Common terms identified between populations of tambaqui sourced from the Balbina and Brumado fish farms.

\begin{tabular}{|c|c|c|c|c|}
\hline Contig ID & $\operatorname{LogFC}$ & Gene symbol & Gene product & GO annotation \\
\hline \multirow[t]{2}{*}{ DN15136_c0_g1_i1 } & 12.54 & IDI1 & Isopentenyl-diphosphate delta isomerase 1 & GO:0006629 lipid metabolic process \\
\hline & & & & GO:0016787 hydrolase activity \\
\hline \multirow[t]{2}{*}{ DN16258_c2_g1_i3 } & 10.71 & creb313b & $\begin{array}{l}\text { Cyclic AMP-responsive element-binding } \\
\text { protein 3-like protein 3-B }\end{array}$ & $\begin{array}{l}\text { GO:0006355 regulation of } \\
\text { transcription, DNA-templated }\end{array}$ \\
\hline & & & & $\begin{array}{c}\text { GO:0001071 nucleic acid binding transcription } \\
\text { factor activity }\end{array}$ \\
\hline DN15150_c1_g1_i17 & 9.98 & AP1G1 & AP-1 complex subunit gamma-1 & GO:0016192 vesicle-mediated transport \\
\hline DN13446_c7_g1_i1 & 9.94 & CNNM3 & Metal transporter CNNM3 & GO:0022857 transmembrane transporter activity \\
\hline DN15804_c1_g1_i17 & 9.65 & SLMAP & Sarcolemmal membrane-associated protein & GO:0008104 protein localization \\
\hline \multirow[t]{2}{*}{ DN13528_c0_g1_i2 } & 9.11 & ACIN1 & Apoptotic chromatin condensation inducer 1 & GO:0042981 regulation of apoptotic process \\
\hline & & & & GO:0003676 nucleic acid binding \\
\hline DN13489_c2_g4_i1 & 8.31 & Pphln1 & Periphilin-1 & $\begin{array}{l}\text { GO:0006355 regulation of } \\
\text { transcription, DNA-templated }\end{array}$ \\
\hline DN14576_c3_g2_i5 & 8.30 & Golt1a & Golgi transport $1 \mathrm{~A}$ & GO:0016192 vesicle-mediated transport \\
\hline DN15916_c5_g1_i3 & 8.28 & NUFIP2 & Nuclear FMR1-interacting protein 2 & GO:0003723 RNA binding \\
\hline \multirow[t]{2}{*}{ DN13598_c6_g1_i5 } & 8.18 & HHIP & Hedgehog-interacting protein & GO:0009966 regulation of signal transduction \\
\hline & & & & GO:0008270 zinc ion binding \\
\hline DN15473_c4_g1_i8 & 8.09 & ADAMTSL5 & ADAMTS-like protein 5 & GO:1901681 sulfur compound binding \\
\hline \multirow[t]{2}{*}{ DN13646_c3_g1_i1 } & 8.02 & ECI2 & Enoyl-CoA delta isomerase 2 & GO:0006629 lipid metabolic process \\
\hline & & & & GO:0000062 fatty-acyl-CoA binding \\
\hline \multirow[t]{2}{*}{ DN13372_c3_g2_i5 } & 7.92 & maea & E3 ubiquitin-protein transferase MAEA & GO:0004842 ubiquitin-protein transferase activity \\
\hline & & & & $\begin{array}{c}\text { GO:0070646 protein modification by small } \\
\text { protein removal }\end{array}$ \\
\hline \multirow[t]{2}{*}{ DN12837_c0_g1_i1 } & 7.77 & MRPL9 & 39S ribosomal protein L9 & GO:0006412 translation \\
\hline & & & & GO:0016072 rRNA metabolic process \\
\hline \multirow[t]{2}{*}{ DN16263_c2_g1_i3 } & 7.64 & PROC & Vitamin K-dependent protein C & $\begin{array}{c}\text { GO:0050727 regulation of inflammatory } \\
\text { response }\end{array}$ \\
\hline & & & & GO:0004252 serine-type endopeptidase activity \\
\hline \multirow[t]{2}{*}{ DN15506_c4_g2_i1 } & 7.55 & $\mathrm{Cd} 7$ & T-cell antigen CD7 & GO:0038023 signaling receptor activity \\
\hline & & & & GO:0016021 integral component of membrane \\
\hline \multirow[t]{2}{*}{ DN14966_c2_g1_i12 } & 7.53 & Igf $2 \mathrm{bp} 2$ & $\begin{array}{c}\text { Insulin-like growth factor } 2 \text { mRNA-binding } \\
\text { protein } 2\end{array}$ & GO:0006810 transport \\
\hline & & & & GO:0003723 RNA binding \\
\hline \multirow[t]{2}{*}{ DN15289_c7_g1_i12 } & 7.46 & KANK1 & $\begin{array}{l}\mathrm{KN} \text { motif and ankyrin repeat do- } \\
\text { main-containing protein } 1\end{array}$ & $\begin{array}{l}\text { GO:0006355 regulation of } \\
\text { transcription, DNA-templated }\end{array}$ \\
\hline & & & & GO:0005515 protein binding \\
\hline \multirow[t]{2}{*}{ DN15264_c5_g2_i9 } & 7.43 & LY75 & Lymphocyte antigen 75 & GO:0006954 inflammatory response \\
\hline & & & & $\begin{array}{c}\text { GO:0004888 transmembrane signaling receptor } \\
\text { activity }\end{array}$ \\
\hline DN15198_c0_g1_i4 & 7.38 & LRRC41 & Leucine-rich repeat-containing protein 41 & $\begin{array}{l}\text { GO:0070646 protein modification by small } \\
\text { protein removal }\end{array}$ \\
\hline \multirow[t]{2}{*}{ DN14189_c1_g1_i5 } & 7.26 & CYP2J2 & Cytochrome P450 2J2 & GO:0006629 lipid metabolic process \\
\hline & & & & GO:0016705 cytochrome p450 activity \\
\hline \multirow[t]{2}{*}{ DN14494_c1_g2_i8 } & 7.13 & PDIA3 & Protein disulfide-isomerase & GO:0006457 protein folding \\
\hline & & & & GO:0016853 isomerase activity \\
\hline \multirow[t]{2}{*}{ DN15995_c4_g1_i11 } & 7.10 & THRAP3 & Thyroid hormone receptor-associated protein 3 & GO:0048511 rhythmic process \\
\hline & & & & GO:0003713 transcription coactivator activity \\
\hline \multirow[t]{2}{*}{ DN14712_c2_g1_i1 } & 7.08 & NLRC3 & NLR family CARD domain-containing protein 3 & GO:0035556 intracellular signal transduction \\
\hline & & & & GO:0005524 ATP binding \\
\hline DN15785_c1_g2_i10 & 6.99 & glyr1 & Putative oxidoreductase GLYR1 & GO:0016491 oxidoreductase activity \\
\hline DN15537_c3_g1_i2 & 6.92 & MTSS1 & Metastasis suppressor protein 1 & GO:0007009 plasma membrane organization \\
\hline
\end{tabular}


Table 2 (cont.)

\begin{tabular}{|c|c|c|c|c|}
\hline Contig ID & $\operatorname{LogFC}$ & Gene symbol & Gene product & GO annotation \\
\hline & & & & GO:0003779 actin binding \\
\hline DN16282_c0_g2_i1 & 6.78 & $\operatorname{cgn}$ & Cingulin & GO:0003774 motor activity \\
\hline DN14613_c2_g2_i4 & 6.62 & impad1 & Inositol monophosphatase 3 & GO:0016791 phosphatase activity \\
\hline DN15794_c0_g1_i5 & 6.61 & Sh3d19 & SH3 domain-containing protein 19 & GO:0007010 cytoskeleton organization \\
\hline \multirow[t]{2}{*}{ DN16271_c6_g1_i11 } & 6.18 & slc29a1 & Solute carrier family 29 member $1 \mathrm{a}$ & GO:0015858 nucleoside transport \\
\hline & & & & $\begin{array}{c}\text { GO:0005337 nucleoside transmembrane } \\
\text { transporter activity }\end{array}$ \\
\hline \multirow[t]{2}{*}{ DN13894_c1_g1_i10 } & 5.48 & apmap & Adipocyte plasma membrane-associated protein & GO:0009058 biosynthetic process \\
\hline & & & & GO:0016844 strictosidine synthase activity \\
\hline \multirow[t]{2}{*}{ DN13396_c1_g2_i5 } & 5.44 & cyp2k1 & Cytochrome P450 2K1 & GO:0030258 lipid modification \\
\hline & & & & GO:0016705 cytochrome p450 activity \\
\hline \multirow[t]{2}{*}{ DN14963_c0_g1_i20 } & 5.35 & Nlrc3 & Protein NLRC3 & GO:0035556 intracellular signal transduction \\
\hline & & & & GO:0005524 ATP binding \\
\hline DN15981_c2_g5_i2 & 5.08 & SUGCT & $\begin{array}{c}\text { Succinate-hydroxymethylglutarate } \\
\text { CoA-transferase }\end{array}$ & $\begin{array}{l}\text { GO:0016782 transferase activity, transferring } \\
\text { sulfur-containing groups }\end{array}$ \\
\hline \multirow[t]{2}{*}{ DN16498_c5_g1_i9 } & 4.97 & $1-2$ & Lactose-binding lectin $1-2$ & GO:0006952 defense response \\
\hline & & & & GO:0030246 carbohydrate binding \\
\hline \multirow[t]{2}{*}{ DN13568_c0_g2_i7 } & 4.91 & AFDN & Afadin & GO:0007155 cell adhesion \\
\hline & & & & GO:0050839 cell adhesion molecule binding \\
\hline \multirow[t]{2}{*}{ DN16570_c8_g1_i10 } & 4.81 & Cyp27a1 & Sterol 26-hydroxylase & GO:0042632 cholesterol homeostasis \\
\hline & & & & GO:0004497 monooxygenase activity \\
\hline \multirow[t]{2}{*}{ DN14390_c2_g4_i1 } & 4.77 & CPT1A & Carnitine O-palmitoyltransferase 1 & GO:0006629 lipid metabolic process \\
\hline & & & & $\begin{array}{l}\text { GO:0016746 transferase activity, transferring } \\
\text { acyl groups }\end{array}$ \\
\hline \multirow[t]{2}{*}{ DN16417_c2_g10_i1 } & 4.77 & CXCL8 & Interleukin-8 & GO:0006955 immune response \\
\hline & & & & GO:0008009 chemokine activity \\
\hline \multirow[t]{2}{*}{ DN13592_c4_g1_i17 } & 4.59 & riox1 & Ribosomal oxygenase 1 & GO:0016570 histone modification \\
\hline & & & & GO:0051213 dioxygenase activity \\
\hline \multirow[t]{2}{*}{ DN13897_c0_g1_i12 } & 4.21 & epd & Ependymin & GO:0007160 cell-matrix adhesion \\
\hline & & & & GO:0005509 calcium ion binding \\
\hline \multirow[t]{2}{*}{ DN16042_c2_g3_i3 } & 4.00 & Ermap & Erythroid membrane-associated protein & GO:0050776 regulation of immune response \\
\hline & & & & GO:0005102 signaling receptor binding \\
\hline DN15608_c1_g1_i4 & 3.82 & DNAJC13 & DnaJ homolog subfamily $\mathrm{C}$ member 13 & GO:0015031 protein transport \\
\hline \multirow[t]{2}{*}{ DN13357_c1_g1_i2 } & 3.53 & Tpk1 & Thiamin pyrophosphokinase 1 & $\begin{array}{c}\text { GO:0009229 thiamine diphosphate biosynthetic } \\
\text { process }\end{array}$ \\
\hline & & & & GO:0004788 thiamine diphosphokinase activity \\
\hline \multirow[t]{2}{*}{ DN15595_c0_g1_i1 } & 3.41 & $\mathrm{PC}$ & Pyruvate carboxylase & GO:0005975 carbohydrate metabolic process \\
\hline & & & & GO:0016874 ligase activity \\
\hline \multirow[t]{2}{*}{ DN13635_c1_g1_i7 } & 3.35 & AKR1B1 & Aldo-keto reductase family 1 member B1 & GO:0005975 carbohydrate metabolic process \\
\hline & & & & GO:0016491 oxidoreductase activity \\
\hline \multirow[t]{2}{*}{ DN16392_c0_g3_i1 } & 3.28 & PDLIM2 & PDZ and LIM domain protein 2 & GO:0005856 cytoskeleton \\
\hline & & & & GO:0003779 actin binding \\
\hline \multirow[t]{2}{*}{ DN15624_c0_g1_i16 } & 3.13 & Srsf5 & Serine/arginine-rich splicing factor 5 & GO:0006397 mRNA processing \\
\hline & & & & GO:0003723 RNA binding \\
\hline \multirow[t]{2}{*}{ DN13615_c0_g9_i2 } & 3.06 & Nop53 & Ribosome biogenesis protein NOP53 & GO:0006364 rRNA processing \\
\hline & & & & GO:0042802 identical protein binding \\
\hline
\end{tabular}

signal transduction, membrane, and cell proliferation or apoptosis. Furthermore, comparative transcriptome-wide investigations associated to the adaptation to different envi- ronmental regimes were reported in sympatric sister species of cichlid fish from Nicaragua, Amphilophus astorquii and A. zaliosus (Elmer et al., 2010), in six catfish species from 


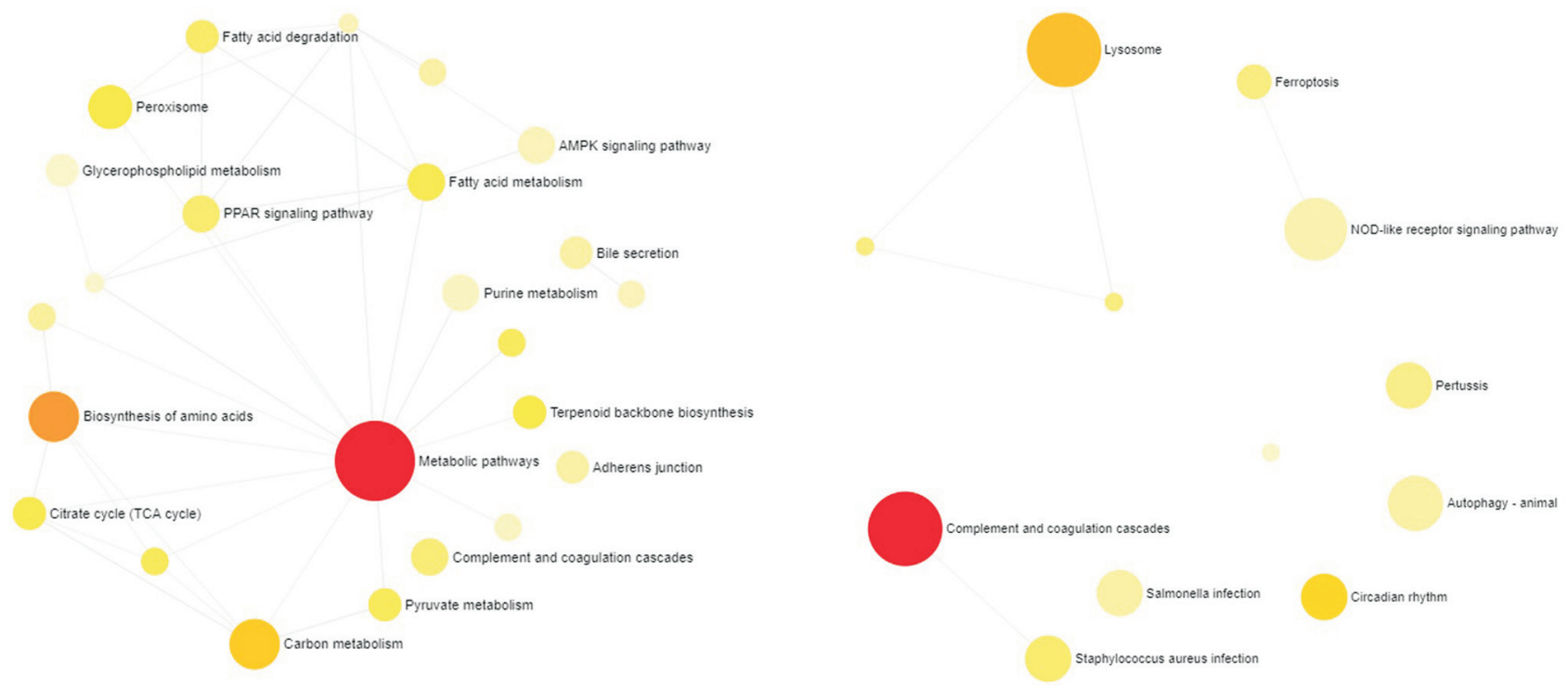

Figure 4 - Functional representation based on KEGG pathways for differentially expressed gene-sets in the Balbina (right side) and Brumado (left side) populations.

Table 3 - List of enriched biological processes represented in the protein-protein interactions (PPI) networks of both the Balbina and Brumado populations.

\begin{tabular}{|c|c|c|c|}
\hline BP Pathways at Balbina & \# Proteins & BP Pathways at Brumado & \# Proteins \\
\hline Lipid metabolic process & 19 & Regulation of biological quality & 28 \\
\hline Organic acid metabolic process & 16 & Response to stress & 27 \\
\hline Carboxylic acid metabolic process & 15 & Regulation of response to stimulus & 24 \\
\hline Cellular lipid metabolic process & 14 & Programmed cell death & 22 \\
\hline Carbohydrate metabolic process & 13 & Apoptotic process & 21 \\
\hline Generation of precursor metabolites and energy & 13 & Regulation of multicellular organismal process & 20 \\
\hline Lipid biosynthetic process & 12 & Immune system process & 20 \\
\hline Nucleotide metabolic process & 12 & Regulation of signal transduction & 19 \\
\hline Response to endogenous stimulus & 12 & Cellular localization & 19 \\
\hline Energy derivation by oxidation of organic compounds & 11 & Catabolic process & 18 \\
\hline Response to hormone stimulus & 10 & Cellular catabolic process & 17 \\
\hline Coenzyme metabolic process & 9 & Establishment of localization in cell & 17 \\
\hline Cofactor metabolic process & 9 & Regulation of apoptotic process & 16 \\
\hline Purine nucleotide metabolic process & 9 & Regulation of programmed cell death & 16 \\
\hline Alcohol metabolic process & 8 & Cellular component assembly & 14 \\
\hline Intracellular protein transport & 8 & Intracellular transport & 13 \\
\hline Peptidyl_amino acid modification & 8 & Response to external stimulus & 13 \\
\hline Purine ribonucleotide metabolic process & 8 & Cellular response to stress & 13 \\
\hline Ribonucleotide metabolic process & 8 & Tissue development & 13 \\
\hline Cellular amino acid metabolic process & 7 & Homeostatic process & 12 \\
\hline Cellular respiration & 7 & Cell migration & 11 \\
\hline Monocarboxylic acid metabolic process & 7 & Enzyme linked receptor protein signaling pathway & 10 \\
\hline Regulation of body fluid levels & 7 & Regulation of immune system process & 10 \\
\hline Steroid metabolic process & 7 & Carbohydrate metabolic process & 10 \\
\hline Coenzyme biosynthetic process & 6 & Hemopoiesis & 9 \\
\hline Cofactor biosynthetic process & 6 & Hematopoietic or lymphoid organ development & 9 \\
\hline Leukocyte migration & 6 & Immune system development & 9 \\
\hline Protein folding & 6 & Purine ribonucleotide metabolic process & 9 \\
\hline
\end{tabular}


Table 3 (cont.)

\begin{tabular}{|c|c|c|c|}
\hline BP Pathways at Balbina & \# Proteins & BP Pathways at Brumado & \# Proteins \\
\hline Steroid biosynthetic process & 6 & Ribonucleotide metabolic process & 9 \\
\hline Aging & 5 & Purine nucleotide metabolic process & 9 \\
\hline Glucose metabolic process & 5 & Cellular homeostasis & 9 \\
\hline Negative regulation of phosphate metabolic process & 5 & Nucleotide metabolic process & 9 \\
\hline Nucleotide biosynthetic process & 5 & Negative regulation of multicellular organismal process & 8 \\
\hline Protein oligomerization & 5 & Regulation of cell migration & 8 \\
\hline Carbohydrate biosynthetic process & 4 & Regulation of catabolic process & 8 \\
\hline Cellular modified amino acid metabolic process & 4 & Regulation of body fluid levels & 8 \\
\hline Energy reserve metabolic process & 4 & Positive regulation of immune system process & 8 \\
\hline Isoprenoid metabolic process & 4 & Cell_substrate adhesion & 7 \\
\hline Regulation of lipid metabolic process & 4 & Regulation of cell adhesion & 7 \\
\hline Response to steroid hormone stimulus & 4 & Regulation of small GTPase mediated signal transduction & 7 \\
\hline Triglyceride metabolic process & 4 & Regulation of response to external stimulus & 7 \\
\hline Glutamine family amino acid metabolic process & 3 & Blood coagulation & 7 \\
\hline Leukocyte chemotaxis & 3 & Coagulation & 7 \\
\hline Protein N_linked glycosylation & 3 & Hemostasis & 7 \\
\hline Protein targeting to membrane & 3 & Behavior & 7 \\
\hline Response to carbohydrate stimulus & 3 & Vasculature development & 7 \\
\hline Response to toxin & 3 & Wound healing & 7 \\
\hline Aerobic respiration & 2 & Regulation of anatomical structure morphogenesis & 7 \\
\hline Cellular modified amino acid biosynthetic process & 2 & Tissue remodeling & 6 \\
\hline \multirow[t]{27}{*}{ Excretion } & 2 & Regulation of Rho protein signal transduction & 6 \\
\hline & & Positive regulation of cell migration & 6 \\
\hline & & Intracellular receptor mediated signaling pathway & 6 \\
\hline & & Regulation of Ras protein signal transduction & 6 \\
\hline & & Cellular component disassembly & 6 \\
\hline & & RNA splicing & 6 \\
\hline & & Regulation of cell morphogenesis & 6 \\
\hline & & Response to drug & 6 \\
\hline & & Muscle cell differentiation & 6 \\
\hline & & Nucleocytoplasmic transport & 6 \\
\hline & & Nuclear transport & 6 \\
\hline & & Leukocyte differentiation & 6 \\
\hline & & RNA splicing & 6 \\
\hline & & Positive regulation of hydrolase activity & 6 \\
\hline & & Actin cytoskeleton organization & 6 \\
\hline & & MRNA processing & 6 \\
\hline & & Positive regulation of cellular component organization & 6 \\
\hline & & Actin filament_based process & 6 \\
\hline & & Positive regulation of cell adhesion & 5 \\
\hline & & Rhythmic process & 5 \\
\hline & & Response to hypoxia & 5 \\
\hline & & Myeloid cell differentiation & 5 \\
\hline & & Leukocyte migration & 5 \\
\hline & & Cellular protein complex assembly & 5 \\
\hline & & Circadian rhythm & 4 \\
\hline & & Intracellular steroid hormone receptor signaling pathway & 4 \\
\hline & & Rho protein signal transduction & 4 \\
\hline
\end{tabular}


Table 3 (cont.)

\begin{tabular}{|c|c|c|c|}
\hline BP Pathways at Balbina & \# Proteins & BP Pathways at Brumado & \# Proteins \\
\hline & & Intrinsic apoptotic signaling pathway & 4 \\
\hline & & Response to carbohydrate stimulus & 4 \\
\hline & & Protein maturation & 4 \\
\hline & & Maintenance of location & 4 \\
\hline & & Post_translational protein modification & 4 \\
\hline & & Transforming growth factor beta receptor signaling pathway & 4 \\
\hline & & Protein import into nucleus & 4 \\
\hline & & Nuclear import & 4 \\
\hline & & Protein folding & 4 \\
\hline & & Extracellular structure organization & 4 \\
\hline & & Regulation of GTPase activity & 4 \\
\hline & & Lymphocyte differentiation & 4 \\
\hline & & Apoptotic signaling pathway & 4 \\
\hline & & Protein import & 4 \\
\hline & & Regulation of MAP kinase activity & 4 \\
\hline & & Ras protein signal transduction & 4 \\
\hline & & Myoblast differentiation & 3 \\
\hline & & Androgen receptor signaling pathway & 3 \\
\hline & & Regulation of JUN kinase activity & 3 \\
\hline & & B cell differentiation & 3 \\
\hline & & Regulation of Rho GTPase activity & 3 \\
\hline & & Maintenance of protein location in cell & 3 \\
\hline & & Regulation of cell shape & 3 \\
\hline & & $\begin{array}{l}\text { Regulation of transforming growth factor beta receptor sig- } \\
\text { naling pathway }\end{array}$ & 3 \\
\hline & & Maintenance of location in cell & 3 \\
\hline & & Maintenance of protein location & 3 \\
\hline & & Cell maturation & 3 \\
\hline & & Protein N_linked glycosylation & 3 \\
\hline & & Protein processing & 3 \\
\hline & & Leukocyte chemotaxis & 3 \\
\hline & & Regulation of JNK cascade & 3 \\
\hline & & Cyclic nucleotide metabolic process & 3 \\
\hline & & Epidermal growth factor receptor signaling pathway & 3 \\
\hline & & Protein polymerization & 3 \\
\hline & & Regulation of Ras GTPase activity & 3 \\
\hline & & Developmental maturation & 3 \\
\hline & & Focal adhesion assembly & 2 \\
\hline & & Bone remodeling & 2 \\
\hline & & Positive regulation of JUN kinase activity & 2 \\
\hline & & Vacuole organization & 2 \\
\hline & & Regulation of cell_cell adhesion & 2 \\
\hline & & Cytoplasm organization & 1 \\
\hline
\end{tabular}

gradient latitudes in the Tibetan Plateau (Ma et al., 2016) as well as in cold- adaptive responses of the Antarctic notothenioid fish, Dissostichus mawsoni (Chen et al., 2008) and Amur carp, Cyprinus carpio haematopterus (Liang et al., 2015 ) to survive freezing polar conditions.
For broodstocks reared in several farming systems, among them, the two analyzed herein, regional adaptation correlated with environmental variables were first report by Nunes (2017) when comparing the eight broodstocks of tambaqui from three different climatic regions in Brazil with 


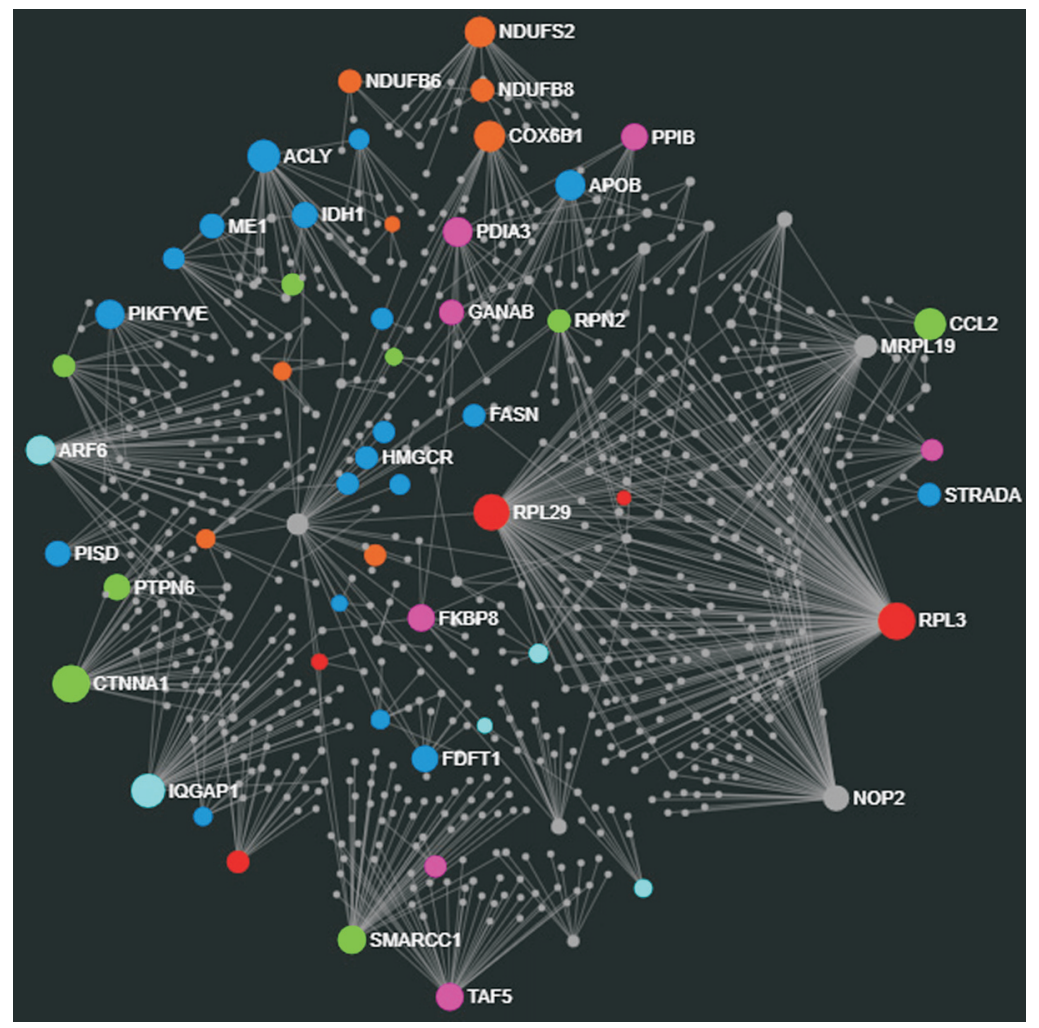

Figure 5 - Enriched hubs highlighting the main biological processes in the protein interaction network of the Balbina population. Hubs with different colors represent prior pathways; orange - energy metabolism, dark blue - lipid metabolism, lemon green - reproductive process, light blue - RNA metabolic process, pink - protein folding, and red - intracellular protein transport. Smaller grey hubs reflect interacting non-differentially expressed genes.

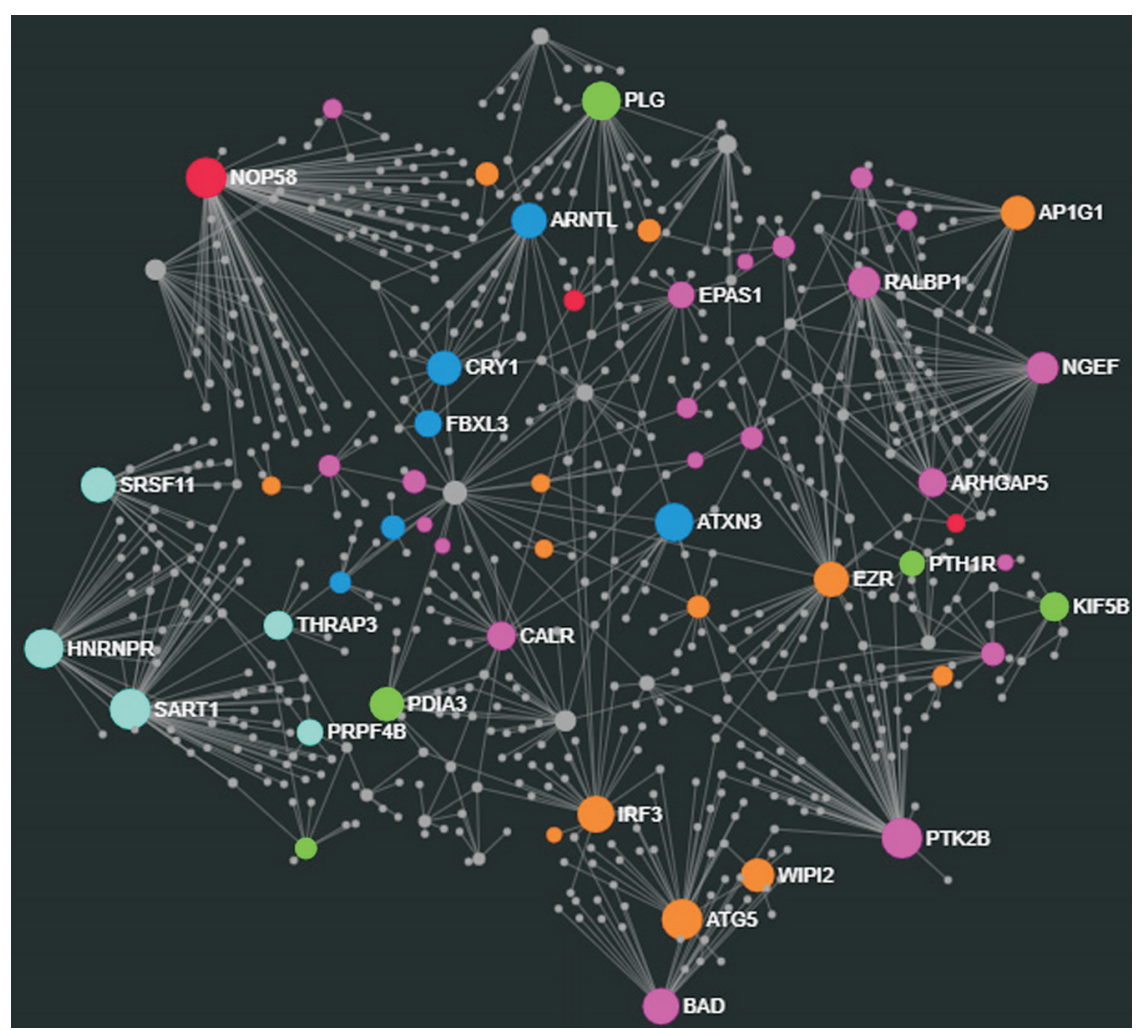

Figure 6 - Enriched hubs highlighting the main biological processes in the protein interaction network of the Brumado population. Hubs with different colors represent prior pathways; orange - cellular response to stress, dark blue - circadian rhythm, lemon green - cellular homeostasis, light blue - mRNA processing, pink - cell signaling, and red - intracellular transport. Smaller grey hubs reflect interacting non-differentially expressed genes. 
high throughput method. Eighteen candidate genes under positive selection were identified through genotyping-bysequencing (GBS) and were related to the immune system, metabolism, biorhythm, and growth. According to Nunes (2017), the climatic contrast of Brazilian region may impose selective forces on the locally adapted populations. Herein, studying juveniles of the two mentioned fish facilities, the upregulation of a set of transcripts revealed the potential genes that are directly involved in the regional adaptation of each population to their living environment. After detailed functional annotation, many genes were assigned to several overlapping pathways (energy metabolism, protein folding, cellular homeostasis, and circadian rhythm), which somewhat corroborated the results described by Nunes (2017).

As stated in the literature, genetic drift strongly influences small populations that decreased in number due to some environmental constraints (Allendorf and Luikart, 2007). Randomly selected animals to form broodstocks for raising tambaqui in farms may have indeed resulted in the loss of variation due to genetic drift. However, the survival of these broodstocks along the years and generations in such a different climate must have also resulted in adaptation to the new captivity situation once, even though losing genetic variability (Santos et al., 2016; Gonçalves et al., 2019), generated healthy fingerlings each reproductive cycle. To proof this affirmation, we may evoke again the work accomplished by Nunes and co-workers, addressing the GBS methodology, where high-density of single-nucleotide polymorphisms (SNPs) were found to be related to thermally adaptive genes (Nunes et al., 2017; Nunes, 2017) as well as in the DEGs found in the present work. On the other hand, only genetic drift would conduct farmed fish to decrease its ability to keep the reproductive success that these parents showed during all these years. While these facts are to be considered simultaneously (genetic drift and adaptive driven genes), there is a good chance, now, to choose target genes in these two populations to commercially improve these fish to the local climate where these animals are being raised.

According to Beitinger et al. (2000), temperature affects virtually all fish physiology. Under thermal stress, metabolic adjustments, including lipid and carbohydrate catabolism, are modulated due to the higher metabolic demand (Wang et al., 2009). Compared to Brumado, at least 14 genes assigned to energy metabolism were enriched in the Balbinas biological network (Figure 5). The overexpressed genes $A P O B$ and $A C L Y$ encode proteins that participate in the lipid metabolism, indicating this may be considered the preferential energy fuel under farming climate conditions in the northern region. Likewise, we found the FADS2 (or $s c d$ ) upregulated gene only in this population, which assures the fluidity and flexibility of cellular membranes by increasing the level of unsaturated fatty acids (Ntambi and Miyazaki, 2004). Remarkably, Oliveira (2014) reported that higher relative transcript levels from liver $S C D-1$ of tambaqui juveniles from farm cages and streams are modulated according to the daily abiotic oscillations in their breeding environment.
Besides energy metabolism, cytoskeleton organization, growth and cell death, and molecular chaperones are the main pathways of generally detected proteins in cellular stress response (Wang et al., 2009). Differentially expressed proteins in the Brumado network were associated with some aspects of the responses to external stimulus (Figure 6). Particularly, heat- $(A T X N 3)$ and hypoxia-responsive genes (TXN2, ldha, BAD, EPAS1, Slc29a1, AGTRAP, PTK2B, rest, and $A d a m 8$ ) were enriched in this population, suggesting that their breeding environment might periodically undergo oscillations in the abiotic parameters. Moreover, in order to maintain homeostasis under variable farming conditions, fish from Brumado expressed PDIA3, KIF5B, PLG, and $P T H 1 R$ genes whose proteins are responsible for cellular homeostasis. In the Balbina population, protein folding was a biologically enriched category that might be related to protein homeostasis against environmental stress (Sherman and Goldberg, 2004). Induced expression of co-chaperones such as $F K B P 3, F K B P 8, S L M A P, P P I B, P D I A 3$, and GANAB genes play an essential role in assisting the proper folding of nascent or stress-damaged proteins (Wegele et al., 2001; Lee et al., 2011). According to Tomalty et al. (2015), the upregulation of chaperones ( $H S P 90$ and $H S P 70$ ) and associated co-chaperone genes (CDC37, AHSA1, FKBP4, CHORDCl, $H S P 5 A$, and $S T I P 1$ ) was strongly related to the management of denatured protein in thermally stressed juvenile Chinook salmon (Oncorhynchus tshawytscha). Taken together, those enriched functional categories in each population represent a relevant picture of the phenotypic plasticity that ensures the maintenance of the homeostatic state when facing the abiotic variables of their farming sites.

Biological clocks play a crucial role in controlling the many functions of organisms, ranging from subcellular processes to behaviour. The basic feature of circadian rhythm involves transcriptional feedback loop regulation being strongly associated with environmental conditions (Prokkola and Nikinmaa, 2018). Both populations of tambaqui differentially expressed genes encoding proteins involved in the positive and negative feedback loops: PERI in Balbina population, and $C R Y 1, A R N T L, A T X N 3$ and FBXL3 in Brumado (Figure 6). According to Mohawk et al. (2012), the expression of $P E R$ and $C R Y$ transcripts drives the generating of the circadian rhythm by repressing the activity of CLOCKARNTL transcription factors. Notably, the upregulation of other clock-controlling genes in Brumado suggests that the seasonal changes in photoperiod in the subtropical region govern the plasticity of the rhythmicity of this population. Indeed, differential expression of circadian clock genes in response to hypoxia and temperature were observed in a cold-adapted salmonid Arctic char (Salvelinus alpinus) providing new insights into rhythmic regulation in fish (Prokkola et al., 2018).

Thus, the suite of genes that were differentially expressed revealed the signatures of local thermal adaptation of each fish population to their environments. For the aquaculture production, the identified candidate genes can be further applied in improvement programs for the creation of 
more heat-tolerant tambaqui fish in the face of forecasted global climate changes.

\section{Acknowledgments}

This research was supported by CAPES (Coordenação de Aperfeiçoamento de Pessoal de Nível Superior) through Pro-Amazon Project \#047/2012, CNPq (Conselho Nacional de Desenvolvimento Científico e Tecnológico) through INCT-ADAPTA II Project \#465540/2014-7 and Universal Calls \#424468/2016-6, and with funding from FAPEAM (Fundação de Amparo à Pesquisa do Estado do Amazonas) through INCT-ADAPTA II Project \#0621187/2017. LMFG was the recipient of the Ph.D. scholarship from CAPES. CHAS and VMFAV are the recipients of the Research Fellowship from CNPq. Special thanks go to Alzira Miranda de Oliveira, Maria de Nazaré Paula-Silva and Fernanda Garcia Dragan for their excellent logistical and technical support. We are additionally grateful to Dr. Adalberto Luis Val for discussions regarding data analysis.

\section{Conflict of Interest}

The authors declare that there is no conflict of interest that could be perceived as prejudicial to the impartiality of the reported research.

\section{Authors Contributions}

LMFG and VMFAV conceived and designed the experiments; LMFG conducted the experiments, collected the samples and performed the molecular protocols; LMFG and JDAA analyzed the data; LMFG, JDAA, CHAS and VMFAV wrote the paper. All authors read, revised and approved the final version.

\section{References}

Allendorf FW and Luikart G (2007) Conservation and the genetics of populations. John Wiley and Sons, Malden.

Altschul SF, Madden TL, Schäffer AA, Zhang J, Zhang Z, Miller W and Lipman DJ (1997) Gapped BLAST and PSI-BLAST: A new generation of protein database search programs. Nucleic Acids Res 25:3389-3402.

Alvares CA, Stape JL, Sentelhas PC, Gonçalves JLM and Sparovek G (2013) Köppen's climate classification map for Brazil. Meteorol zeitschrift 22:711-728.

Araújo-Lima C and Goulding M (1998) Os frutos do tambaqui: Ecologia, conservação e cultivo na Amazônia. Sociedade Civil Mamirauá, Tefé, 186 p.

Bates DM, Ellis B, Smith C, Irizarry R, Tierney L, Huber W, Leisch F, Iacus S, Maechler M, Hornik K et al. (2004) Bioconductor: Open software development for computational biology and bioinformatics. Genome Biol 5:1-16.

Beitinger TL, Bennett WA and Mccauley RW (2000) Temperature tolerances of North American freshwater fishes exposed to dynamic changes in temperature. Environ Biol Fishes 58:237-275.

Bellard C, Bertelsmeier C, Leadley P, Thuiller W and Courchamp F (2014) Impacts of climate change on the future of biodiversity. Ecol Lett 15:365-377.
Bolger AM, Lohse M and Usadel B (2014) Trimmomatic: A flexible trimmer for Illumina sequence data. Bioinformatics 30:2114-2120.

Campos DF, Braz-Mota S, Val AL and Almeida-Val VMF (2019) Predicting thermal sensitivity of three Amazon fishes exposed to climate change scenarios. Ecol Indic 101:533-540.

Chen Z, Cheng CHC, Zhang J, Cao L, Chen L, Zhou L, Jin Y, Ye H, Deng C, Dai $Z$ et al. (2008) Transcriptomic and genomic evolution under constant cold in Antarctic notothenioid fish. Proc of the Natl Acad Sci U S A 105:12944-12949.

CONCEA - Conselho Nacional de Controle de Experimentação Animal (2013) Diretrizes da prática de eutanásia do CONCEA. Conselho Nacional de Controle de Experimentação Animal, Brasília.

DNOCS - Departamento Nacional de Obras Contra as Secas (2009) Relatório 2008. Departamento Nacional de Obras Contra as Secas, Fortaleza.

Dragan FG (2019) Influência das mudanças climáticas sobre as respostas gênicas adaptativas do tambaqui (Colossoma macropomum, Cuvier 1818) aclimatizado em regiões climáticas distintas. $\mathrm{PhD}$ Thesis, Universidade Nilton Lins, Manaus, $124 \mathrm{p}$.

Elmer KR, Fan S, Gunter HM, Jones JC, Boekhoff S, Kuraku S and Meyer A (2010) Rapid evolution and selection inferred from the transcriptomes of sympatric crater lake cichlid fishes. Mol Ecol 19:197-211.

Fé-Gonçalves LM, Paula-Silva MN, Val AL and Almeida-Val VMF (2018) Differential survivorship of congeneric ornamental fishes under forecasted climate changes are related to anaerobic potential. Genet Mol Biol 41:107-118.

Fisch G, Marengo JA and Nobre CA (1998) The climate of Amazonia - A review. Acta Amaz 28:101-126.

Gonçalves RA, Santos CHA, Sá-Leitão CS, Souza ÉMS and Almeida-Val VMF (2019) Genetic basis of Colossoma macropomum broodstock: Perspectives for an improvement program. J World Aquac Soc 50:633-644.

Grabherr MG, Haas BJ, Yassour M, Levin JZ, Thompson DA, Amit I, Adiconis X, Fan L, Raychowdhury R, Zeng Q et al. (2011) Full-length transcriptome assembly from RNA-Seq data without a reference genome. Nat Biotechnol 29:644-652.

IBGE - Instituto Brasileiro de Geografia e Estatística (2016) Produção da Pecuária Municipal. v. 44. IBGE, Rio de Janeiro, 51 pp.

Langmead B and Salzberg SL (2012) Fast gapped-read alignment with Bowtie 2. Nat Methods 9:357-359.

Lee YS, Smith RS, Jordan W, King BL, Won J, Valpuesta JM, Naggert JK, Nishina PM (2011) Prefoldin 5 is required for normal sensory and neuronal development in a murine model. J Biol Chem 286:726-736.

Lemgruber RS, Marshall NAA, Ghelfi A, Fagundes DB and Val AL (2013) Functional categorization of transcriptome in the species Symphysodon aequifasciatus Pellegrin 1904 (Perciformes: Cichlidae) exposed to benzo[a]pyrene and phenanthrene. PLoS One 8:e81083.

Li B and Dewey CN (2011) RSEM: Accurate transcript quantification from RNA-seq data with or without a reference genome. BMC Bioinformatics 12:41-74.

Liang L, Chang Y, He X and Tang R (2015) Transcriptome analysis to identify cold-responsive genes in amur carp (Cyprinus carpio haematopterus). PLoS One 10:e0130526.

Logan CA and Buckley BA (2015) Transcriptomic responses to environmental temperature in eurythermal and stenothermal fishes. J Exp Biol 218:1915-1924. 
Ma X, Dai W, Kang J, Yang L and He S (2016) Comprehensive transcriptome analysis of six catfish species from an altitude gradient reveals adaptive evolution in Tibetan fishes. G3 Genes, Genomes, Genet 6:141-148.

Mirande JM (2010) Phylogeny of the family Characidae (Teleostei: Characiformes): from characters to taxonomy. Neotrop Ichthyol 8:385-568.

Mohawk J, Green C and Takahashi J (2012) Central and peripheral circadian clocks in mammals. Annu Rev Neurosci 35:445462.

Morais IS and O'Sullivan FLA (2017) Biologia, habitat e cultivo do tambaqui Colossoma macropomum (CUVIER, 1816). Sci Amaz 1:81-93.

Moro GV, Rezende F, Alves AL, Hashimoto DT, Varela ES and Torati LS (2013) Espécies de peixe para piscicultura. In: Rodrigues APO, Lima AF, Alves AL, Rosa DK, Torati LS and Santos VRM (eds) Piscicultura de água doce: Multiplicando conhecimento. EMBRAPA, Brasília, pp 29-70.

Ntambi J and Miyazaki M (2004) Regulation of stearoyl-CoA desaturases and role in metabolism. Prog Lipid Res 43:91104.

Nunes JRS (2017) SNP discovery, high-density genetic map construction, and identification of genes associated with climate adaptation, and lack of intermuscular bone in tambaqui (Colossoma macropomum). $\mathrm{PhD}$ Thesis, Universidade de São Paulo, Piracicaba, 75 p.

Nunes JRS, Liu S, Pértille F, Perazza CA, Villela PMS, AlmeidaVal VMF, Hilsdorf AWS, Liu Z and Coutinho LL (2017) Large-scale SNP discovery and construction of a high-density genetic map of Colossoma macropomum through genotyping-by-sequencing. Sci Rep 7:1-11.

Oliveira AM (2014) Influência da temperatura ambiental e dos cenários climáticos futuros sobre os ácidos graxos $\omega-3$ e $\omega-6$ e desempenho zootécnico do tambaqui (Colossoma macropomum). PhD Thesis, Instituto Nacional de Pesquisas da Amazônia, Manaus, 136 p.

Oomen RA and Hutchings JA (2017) Transcriptomic responses to environmental change in fishes: Insights from RNA sequencing. Facets 2:610-641.

Ostrensky A, Borguetti JR and Soto D (2008) Aquicultura no Brasil. O desafio é crescer. Secretaria Especial de Aquicultura e Pescas, Brasília, pp 276.

Pörtner HO and Peck MA (2010) Climate change effects on fishes and fisheries: Towards a cause-and-effect understanding. J Fish Biol 77:1745-1779.

Prokkola JM and Nikinmaa M (2018) Circadian rhythms and environmental disturbances - Underexplored interactions. J Exp Biol 221:jeb179267.

Prokkola JM, Nikinmaa M, Lewis M, Anttila K, Kanerva M, Ikkala K, Seppänen E, Kolari I and Leder EH (2018) Cold temperature represses daily rhythms in the liver transcriptome of a stenothermal teleost under decreasing day length. J Exp Biol jeb. 170670 .

Robinson MD, McCarthy DJ and Smyth GK (2009) edgeR: A Bioconductor package for differential expression analysis of digital gene expression data. Bioinformatics 26:139-140.

Saint-Paul U (1986) Potential for aqualculture of South American freshwater fishes: A review. Aquaculture 54:205-240.

Santos CHA, Santana GX, Sá-Leitão CS, Paula-Silva MN and Almeida-Val VMF (2016) Loss of genetic diversity in farmed populations of Colossoma macropomum estimated by microsatellites. Anim Genet 47:373-376.

Schulte PM (2001) Environmental adaptations as windows on molecular evolution. Comp Biochem Physiol - B Biochem Mol Biol 128:597-611.

Sherman MY and Goldberg AL (2004) Cellular defenses against unfolded proteins. Neuron 29:15-32.

Tomalty KMH, Meek MH, Stephens MR, Rincón G, Fangue NA, May BP and Baerwald MR (2015) Transcriptional response to acute thermal exposure in juvenile Chinook salmon determined by RNAseq. G3 5:1335-1349.

Wang P, Bouwman FG and Mariman ECM (2009) Generally detected proteins in comparative proteomics - A matter of cellular stress response? Proteomics 9:2955-2966.

Wegele H, Müller L and Buchner J (2001) Hsp70 and Hsp90 - A relay team for protein folding. In: Amara SG, Bamberg E, Grunicke H, Jahn R, Lederer WJ, Miyajima A, Murer H, Offermanns S, Schultz G and Schweiger M (eds) Reviews of Physiology, Bochemistry and Pharmacology. Springer, Berlin, pp 1-44.

Xia J, Benner MJ and Hancock REW (2014) NetworkAnalyst - Integrative approaches for protein-protein interaction network analysis and visual exploration. Nucleic Acids Res 42:167174.

Yi S, Wang S, Zhong J and Wang W (2016) Comprehensive transcriptome analysis provides evidence of local thermal adaptation in three loaches (Genus: Misgurnus). Int J Mol Sci 17:1-13.

\section{Internet Resources}

Andrews S (2010) FastQC - A quality control tool for high throughput sequence data, http://www.bioinformatics.babraham.ac.uk/projects/fastqc/ (accessed 16 February 2019).

Climatempo (2019) Climatempo - O melhor site de meteorologia do Brasil, https://www.climatempo.com.br/ (accessed 10 January 2019).

CPTEC/INPE (2019) Centro de Previsão de Tempo e Estudos Climáticos - CPTEC/INPE, https://www.cptec.inpe.br/ (accessed 10 January 2019).

National Center for Biotechnology Information/Sequence Read Archive (NCBI/SRA), https://www.ncbi.nlm.nih.gov/sra (accessed 5 June 2019).

NetworkAnalyst - comprehensive gene expression analysis, meta-analysis \& network biology, https://www.networkanalyst.ca/ (accessed 12 August 2019).

Trinotate - Transcriptome Functional Annotation and Analysis, https://trinotate.github.io/ (accessed 11 July 2018).

\section{Supplementary material}

The following online material is available for this article:

Table S1 - List of prior hubs that formed the biological network of the Balbina population.

Table S2 - List of prior hubs that formed the biological network of the Brumado population.

\section{Associate Editor: Guilherme Corrêa de Oliveira}

License information: This is an open-access article distributed under the terms of the Creative Commons Attribution License (type CC-BY), which permits unrestricted use, distribution and reproduction in any medium, provided the original article is properly cited. 